\title{
The effect of liquid temperature and viscosity on the amplitude-frequency characteristics of a viscotic torsion damper
}

Wojciech Homik, Ph. D.

Rzeszów University of Technology, Poland

\section{ABSTRACT}

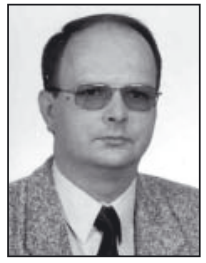

The article discusses causes of the appearance of transverse, longitudinal and torsional crankshaft vibrations in multi-cylinder internal combustion engines. Particular attention is paid to the torsional vibration which is the most severe threat to engine crankshafts. Damping methods making use of torsion dampers are presented. With the reference to viscotic dampers, problems with their damping efficiency are discussed in the context of viscosity changes of the damping liquid. The article also presents the amplitude-frequency characteristics of a series of viscotic dampers, which were recorded experimentally on the research rig and on a real object. An idea of vibration damper metric is given.

Key words: torsional vibration; torsional vibration damping; torsional vibration dampers; crankshaft; amplitude-frequency characteristics; liquid viscosity; damper metric

\section{INTRODUCTION}

The internal combustion engine. Could the designers of the first internal combustion engines predict that their construction would become the source of progress and development of transport facilities?
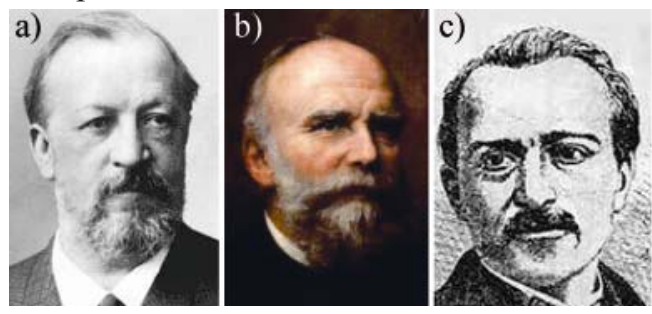

d)

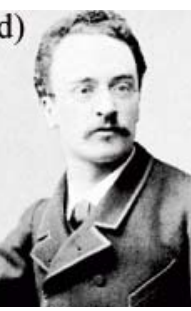

Fig. 1. Designers of piston internal combustion engines [12]: a) NicolausAugust-Otto, b) Eugenem Langenem, c) Étienne Lenoir, d) Rudolf Diesel

Surely, none of them expected that the basic idea of their construction (Fig. 2, 3, 4) [12] which changes the reciprocating linear motion into the rotary motion would remain in a practically unchanged form until now.

The forces acting on the engine crankshaft system include:

- gas pressure forces $\mathrm{P}_{\mathrm{g}}$,

- inertial forces $\mathrm{P}_{\mathrm{b}}$.

The gas pressure forces $\mathrm{P}_{\mathrm{g}}$ and the inertial forces $\mathrm{P}_{\mathrm{b}}$ are periodically changing forces. In four-stroke engines the period of the inertial forces is equal to one full revolution of the engine crankshaft, while that of the pressure forces - to two

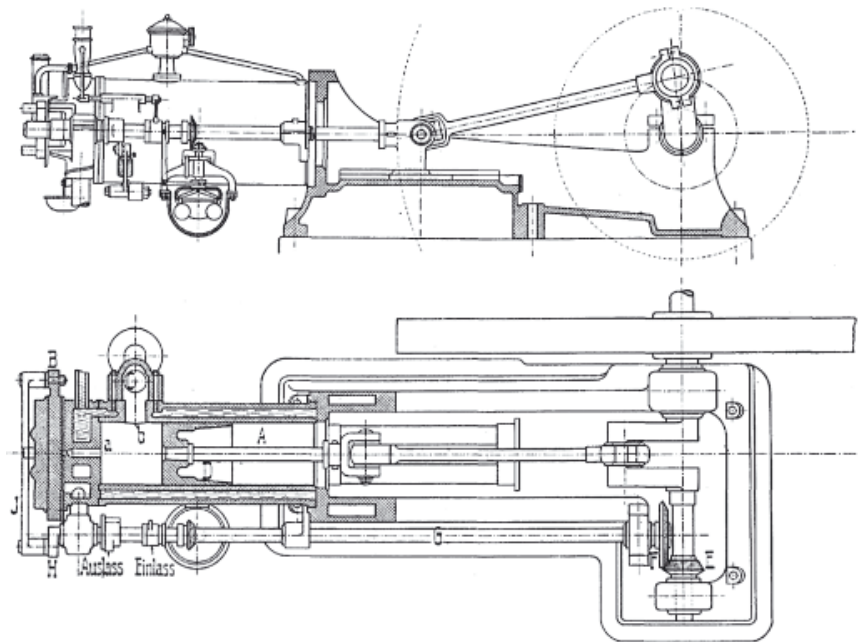

Fig. 2. Design of Otto engine of 1876

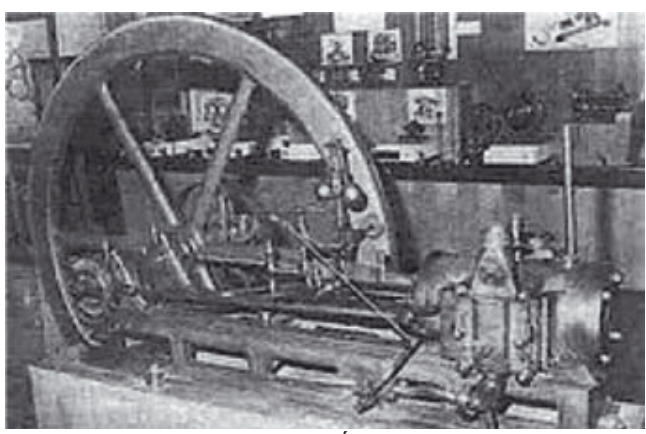

Fig. 3. Construction of Étienne Lenoir engine 


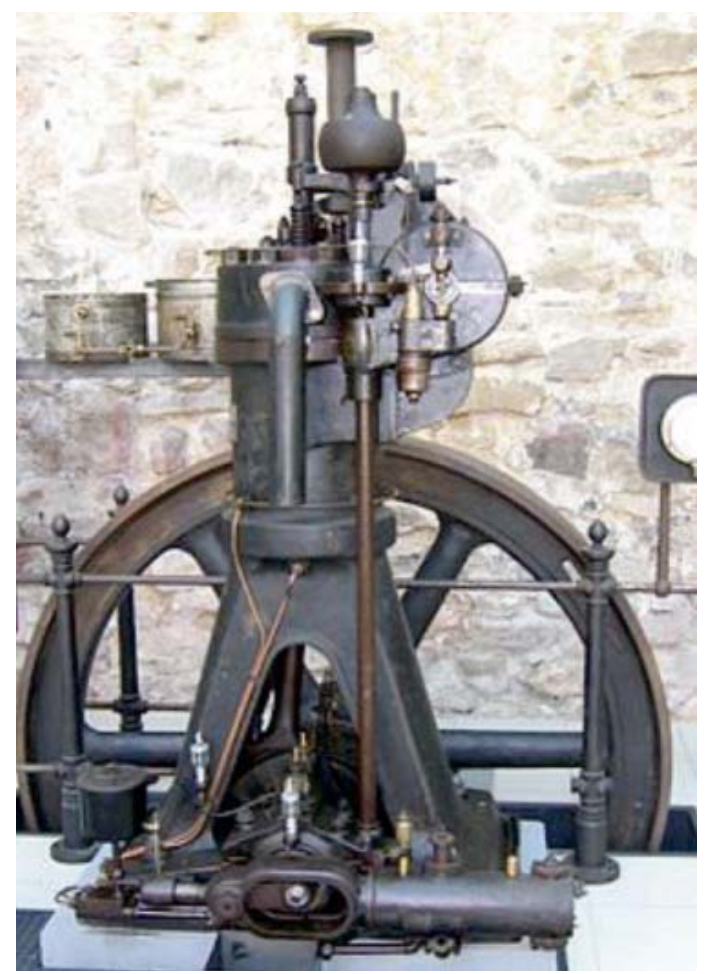

Fig. 4. Construction of Rudolf Diesel engine

revolutions. In two-stroke engines the latter period is also equal to one full crankshaft revolution.

The resultant force of the above forces is their sum $[1,13$, $14,15,16]$

$$
\mathrm{P}=\mathrm{P}_{\mathrm{g}}+\mathrm{P}_{\mathrm{b}}
$$

The analysis of changes of the resultant force $\mathrm{P}$ as a function of the crank angle $\varphi(t)$ reveals that at the final compression phase and the initial expansion phase the inertial forces unload the crankshaft-piston system, while in the remaining time they are the sources of extremely high load, especially during the suction and exhaust strokes.

Since in general, the axis of the connecting rod is not in line with the cylinder axis during engine operation, the resultant force $\mathrm{P}$ acting on the piston is not transmitted solely by the connecting rod. It is shifted towards the piston pin axis, in which it is decomposed into two components:

- N component acting on the cylinder surface,

- S component acting along the connecting rod axis.

The magnitude of the force $\mathrm{N}$ depends on the coefficient $\lambda$, being the ratio of the crank arm length $r$ and the length $L$ of the connecting rod (the larger $\lambda$, the larger the force $\mathrm{N}$ ).

The force $\mathrm{S}$ acting along the connecting rod axis acts on the crank, where it is again decomposed into two component forces: the $\mathrm{T}$ component which is tangential to the circle described by the crank, and the radial component $\mathrm{K}$ acting along the temporary crank arm position.

The above forces are given by the relations:

$$
\begin{gathered}
T=S \sin (\varphi+\beta)=\frac{P}{\cos \beta} \sin (\varphi+\beta) \\
K=S \cos (\varphi+\beta)=\frac{P}{\cos \beta} \cos (\varphi+\beta)
\end{gathered}
$$

where:

$\varphi-$ crank angle,

$\beta-\quad$ angle of crankshaft deflection from cylinder axis.
The periodic nature of changes of the gas pressure forces $\mathrm{P}_{\mathrm{g}}$ and the inertial forces $\mathrm{P}_{\mathrm{p}}$ is the source of the following types of crankshaft vibrations $[1,14,15]$ :

- transverse vibration,

- longitudinal vibration,

- torsional vibration.

These vibrations are sort of protection measure, taken by the engine components made of elastic materials, which consists in yielding to the applied load by gradual absorption of the transmitted energy in the form of vibrations. Many engine components, including the abovementioned crankshafts, would be damaged very fast if they did not have the ability to absorb the energy in the form of elastic deformations (Fig. 5).

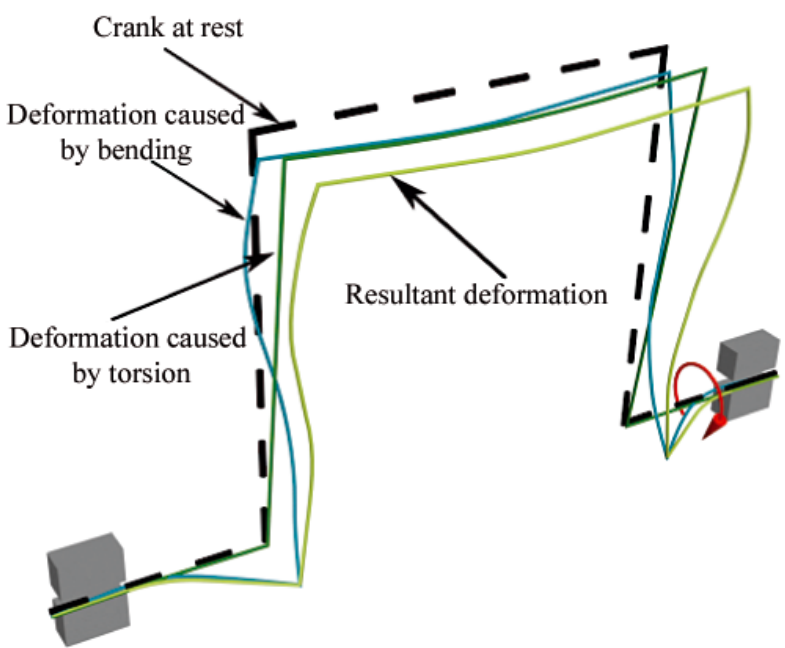

Fig. 5. Sample elastic crank deformations caused by T force

\section{VIBRATIONS}

\section{Transverse vibration}

The transverse vibration of the crankshaft, also sometimes referred to as the bending vibration, is caused by the action of periodically changing radial forces $\mathrm{K}$ on the crank pins. This vibration results in bending the shaft between the bearings (Fig. 6)

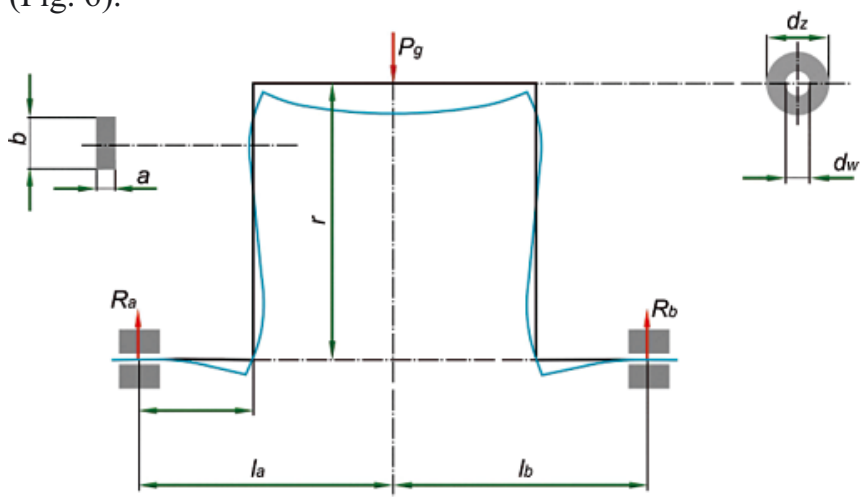

Fig. 6. Shaft deflection between bearings

\section{Longitudinal vibration}

The longitudinal vibration of the crankshaft is directly related to its transverse vibration. Any shaft deflection causes its axial shift (Fig. 7).

In most cases this vibration does not disturb the engine operation (especially in motor-car multi-cylinder internalcombustion engines) and is not a severe threat to the durability of the crankshaft, which reveals relatively high rigidity. 


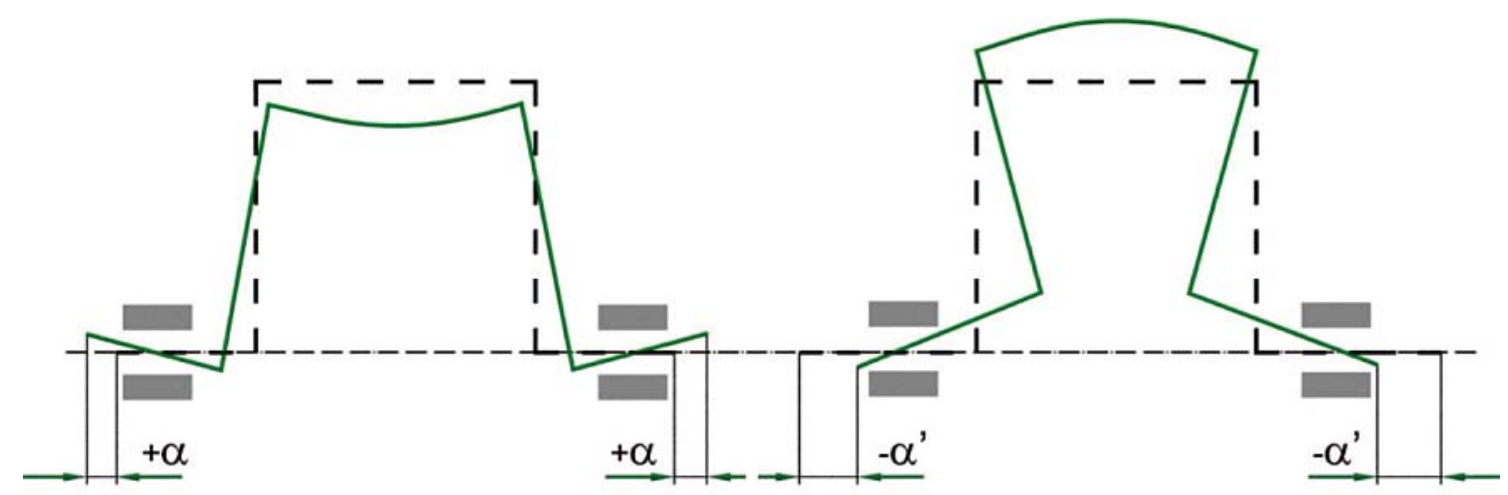

Fig. 7. Longitudinal crankshaft vibration

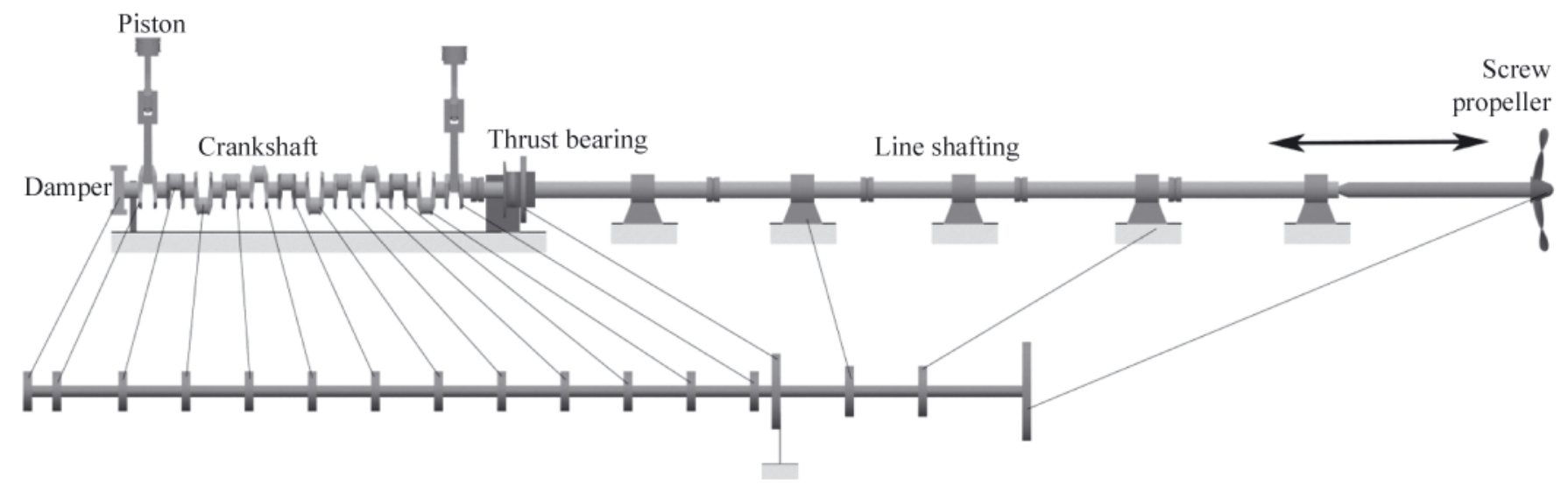

Fig. 8. Real and virtual propulsion system of a watercraft

It should be stressed, however, that this vibration can be a severe problem in marine large-power engines. They make the entire structure (Fig. 8), consisting of the engine crankshaft, the flywheel, the line shafting and the screw propeller, move periodically along its axis. The amplitude of the longitudinal vibration of this structure depends in practice on individual design solutions of the screw propeller, in particular on the number of paddles [14].

\section{Torsional vibration}

Among all forces acting on the piston-crankshaft system, the force which makes the crankshaft rotate is the $\mathrm{T}$ force tangential to the circle described by the crank.

This force affects the engine torque which is equal to

$$
M(\varphi)=T(\varphi) \cdot r=\frac{P}{\cos \beta} r \sin (\varphi+\beta)
$$

where:

$\mathrm{M}(\varphi)$ - shaft torque,

$\mathrm{T}(\varphi)$ - tangential force,

r $\quad$ - crank arm length.

The $\mathrm{T}$ force, which is one of two components of the $\mathrm{S}$ force acting along the connecting rod axis, is a periodically changing force. Its period is equal to $2 \pi$ for two-stroke engines and $4 \pi$ for four-stroke engines. The changing $\mathrm{T}$ force is a source of accelerations in the rotational motion of the engine crankshaft, and torsional vibrations, as a further consequence (Fig. 9), which change with the changed rotational speed of the shaft [15].

Among all vibrations, the torsional vibration creates the biggest threat to the crankshaft.

It is noteworthy that the crankshaft deflection is only limited by the torsional stiffness of the shaft, and the amplitude of the torsional vibration can exceed the permissible values. In case of total lack of damping, the curve according to which the vibration changes tends to infinity for any speed generating a resonance harmonic.

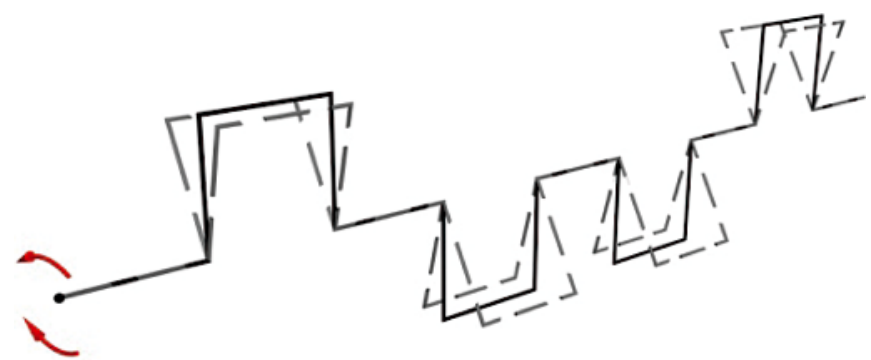

Fig. 9. Torsional crankshaft vibration

Torsion break of the shaft takes place when the permissible value of the amplitude $\varphi_{\text {dop }}$ (permissible torsion angle) is exceeded

$$
\varphi_{\mathrm{rz}}>\varphi_{\mathrm{dop}}
$$

The permissible value of the torsion angle $\varphi_{\text {dop }}$ depends on the conditions of engine operation and is determined by general tolerance of geometrical parameters. A term which is frequently used for its easy comparison is the elementary torsion angle $[2,3]$ :

$$
\varphi^{\prime}=\frac{\varphi}{1}=\frac{\mathrm{M}_{\mathrm{S}}}{\mathrm{GI}_{0}}\left[\frac{\mathrm{rad}}{\mathrm{m}}\right]
$$

where:

$\mathrm{M}_{\mathrm{s}}$ - torque,

$\mathrm{G}$ - torsional modulus,

$\mathrm{I}_{\mathrm{o}}-$ polar moment of inertia 
For steel propeller shafts and fluctuating loads:

$$
\varphi_{\mathrm{dop}}^{\prime}=0.004\left[\frac{\mathrm{rad}}{\mathrm{m}}\right]
$$

while for alternating loads:

$$
\varphi_{\text {dop }}^{\prime}=0.0025\left[\frac{\mathrm{rad}}{\mathrm{m}}\right]
$$

The permissible values of the torsion angle are most frequently within the limits:

$$
\varphi_{\text {dop }}^{\prime}=(0.002 \div 0.01)\left[\frac{\mathrm{rad}}{\mathrm{m}}\right]
$$

For the shaft revealing changing torsional stiffness (profiled crankshaft) the basic condition (6) takes the form:

$$
\varphi^{\prime}=\frac{\mathrm{M}_{\mathrm{S}}}{\mathrm{G}} \sum_{\mathrm{i}=1}^{\mathrm{n}} \frac{1}{\mathrm{I}_{0 \mathrm{i}}} \leq \varphi_{\mathrm{dop}}^{\prime}
$$

\section{TYPES OF TORSION DAMPERS}

Detecting the torsional vibration of the engine crankshaft is more difficult than in case of other vibration types. Its presence can be sometimes testified by, for instance, non-uniform engine operation, the timing gear of which is driven by the torsionally vibrating crankshaft via a mechanical transmission (for instance belt, chain, or gear transmission).

The variety of vibration forms and the existence of different harmonics of the tangential force $\mathrm{T}$ are the reasons why the crankshaft can work in the zone of resonance at different rotational speeds of the engine.

The engine operation in critical (resonance) conditions is most frequently avoided by the use of vibration dampers (Fig. 10).

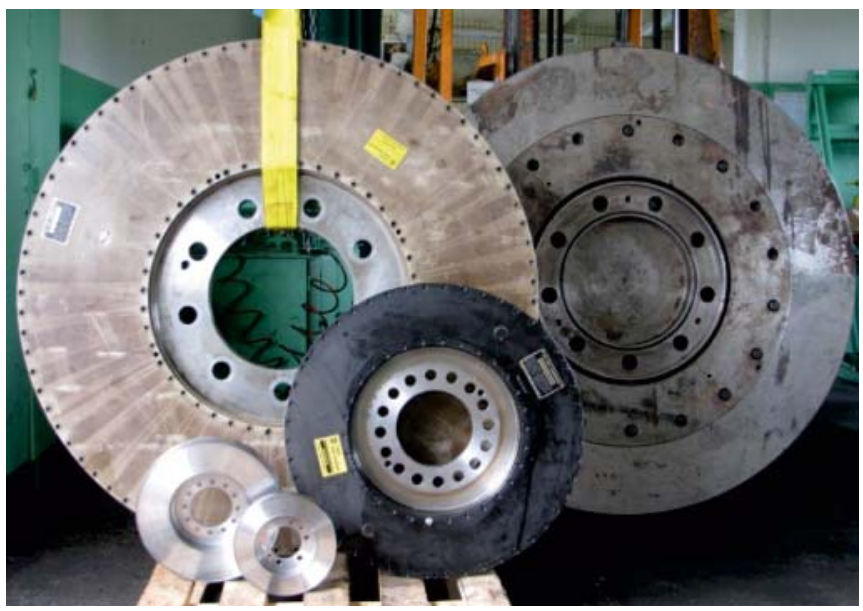

Fig. 10. Torsion dampers

Their task is to decrease the amplitude of the resonant torsional vibrations of the engine crankshaft. A properly designed (selected, "tuned") torsion damper provides opportunities for decreasing the amplitude of torsion vibration resonance by even as much as ten times. But we should keep in mind that each damper consumes part of the effective power of the engine.

In the past, the threat coming from torsional vibrations of watercraft power transmission systems was minimised using the following types of dampers:

- frictional dampers,

- rubber dampers,

- viscotic dampers,

- spring dampers.
The above named dampers are typical dynamic resonant vibration dampers in which the vibration is damped using the inertia force $[4,5]$. Despite a common name, the dynamic dampers differ between each other not only by constructional designs but, what is more important, also by operating characteristics [10]. It is also noteworthy that these dampers work effectively only within a certain range of rotational speed.

Among all the above mentioned dampers, it is the viscotic dampers which have found the widest application in watercraft power transmission systems. This most likely results from their simple structure, operating reliability, relatively simple manufacturing technology and low production costs, as compared to other solutions.

Nowadays the viscotic torsion dampers are filled with stabilised silicone oils of AK type produced by Bayer and Wacker (Fig. 11). A basic parameter characterising the oil (like any other real liquid) is its viscosity, defined as the internal resistance which appears during displacement of a liquid layer. In this sense the viscosity is decisive about fluid friction: the higher viscosity, the larger the internal friction of the liquid.

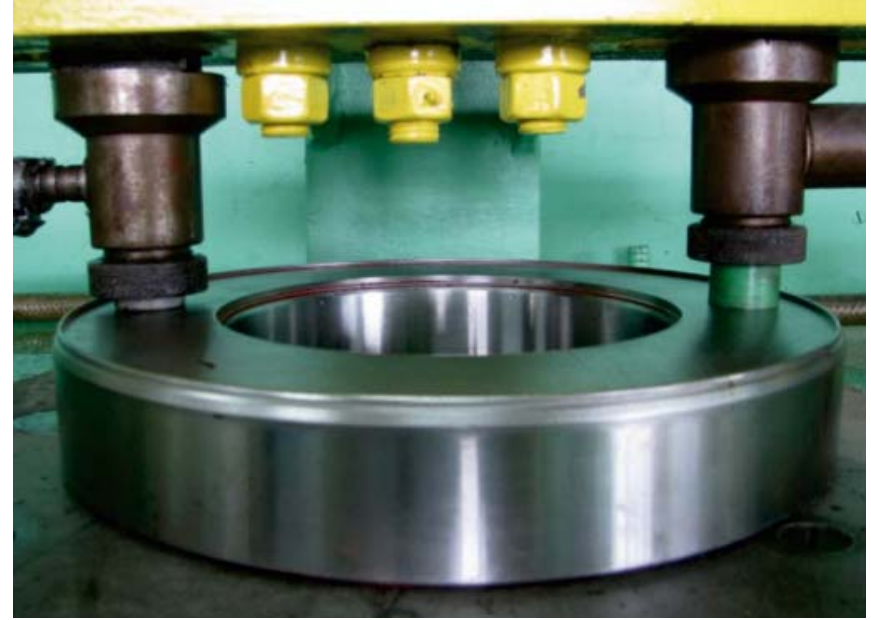

Fig. 11. Process of filling the viscotic torsion damper [8]

The silicone AK oils are watery clear liquids, the viscosity of which changes with shear velocity changes (Fig. 12).

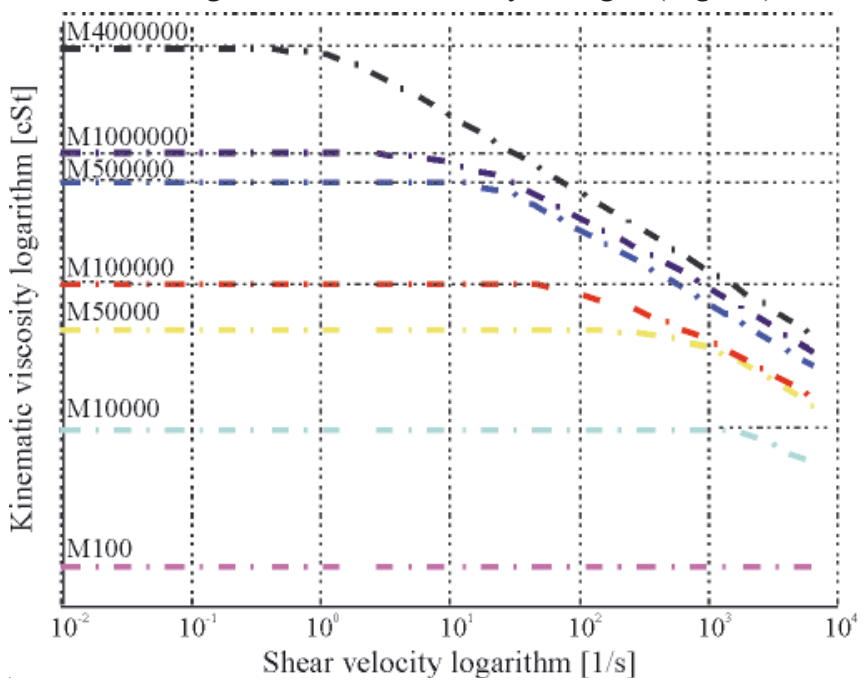

Fig. 12. Kinematic viscosity logarithm vs. shear velocity logarithm [20]

Changes of liquid viscosity are caused not only by the increase of its shear velocity but also by changes of the operating temperature and oil ageing processes $[6,7]$. Cases are well-known in which improper use of the damper has resulted 
in remarkable increase of the oil viscosity and change of the oil aggregation state (Fig. 13) [9, 10]

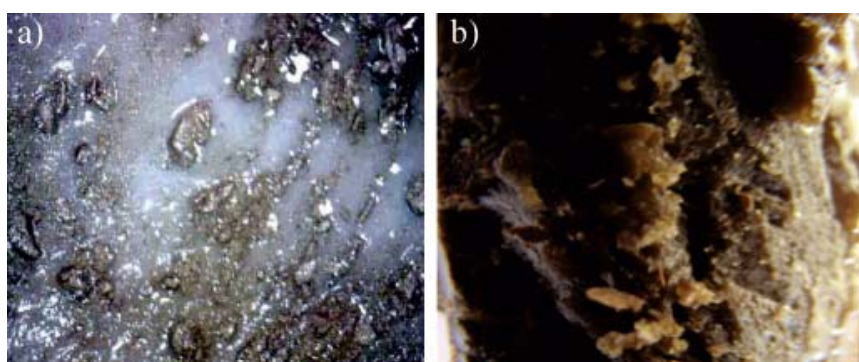

Fig. 13. Samples of oils - magnified 200 times: a) oil with particles of damper parts, $\boldsymbol{b})$ oil having the consistence of a solid body

Oil viscosity changes cannot be neglected at the stage of selection (designing) of the viscotic damper for a certain power transmission unit [11]. When selecting the damper, calculations are performed to determine an optimal liquid viscosity, i.e. the viscosity for which the value of the energy dissipated by the damper in given operating conditions reaches the maximum.

As a rule, the damper calculations take into account the nonlinearity of the liquid. Among other publications, this issue was discussed in detail in the work entitled "Optimisation of the viscotic torsion damper" [4]. In that work, in order to define the effect of liquid nonlinearity of the efficiency of the viscotic torsion damper, the damping coefficient $\alpha$ which, as mentioned above, depends on the liquid viscosity, was described using the following functions:

$$
\begin{gathered}
\left.\alpha=\alpha_{N}\left(1-\mathrm{c}\left|\dot{\varphi}_{\mathrm{o}}-\dot{\varphi}_{\mathrm{p}}\right|\right), \alpha_{\mathrm{N}} \in<0, \infty\right) \\
\alpha=\alpha_{\mathrm{N}} \exp \left(1-\mathrm{c}\left|\dot{\varphi}_{\mathrm{o}}-\dot{\varphi}_{\mathrm{p}}\right|\right), \quad \mathrm{c} \geq 0 \\
\alpha=\alpha_{\mathrm{N}} \dot{\gamma}^{(\mathrm{n}-1)}
\end{gathered}
$$

where:

$\alpha_{\mathrm{N}} \quad-$ damping coefficient of a damper with Newtonian liquid,

$\dot{\varphi}_{\mathrm{o}}-\dot{\varphi}_{\mathrm{p}}-$ relative speed of the casing with respect to the ring,

$c \quad-$ coefficient taking into account the effect of the shear velocity on viscosity.

Sample results of calculations are shown in Figs. 14 - 18.

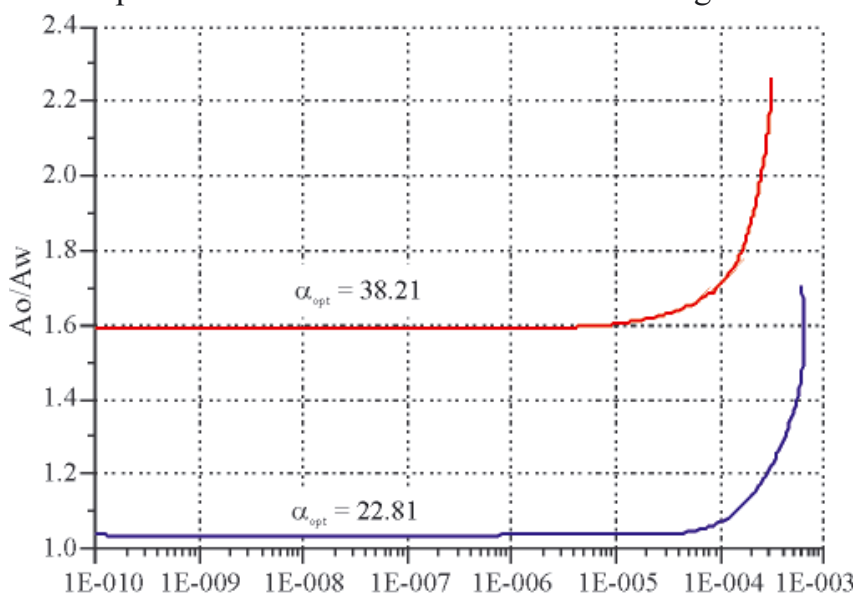

Fig. 14. Casing vibration amplitude vs. logarithm c

At present, for technological reasons the viscotic torsion dampers make use of oils the viscosity of which does not exceed 300000 [cSt] at temperature of $20^{\circ} \mathrm{C}$. In those cases, when modelling the viscotic torsion dampers we can assume that the analysed liquid is the linear liquid.

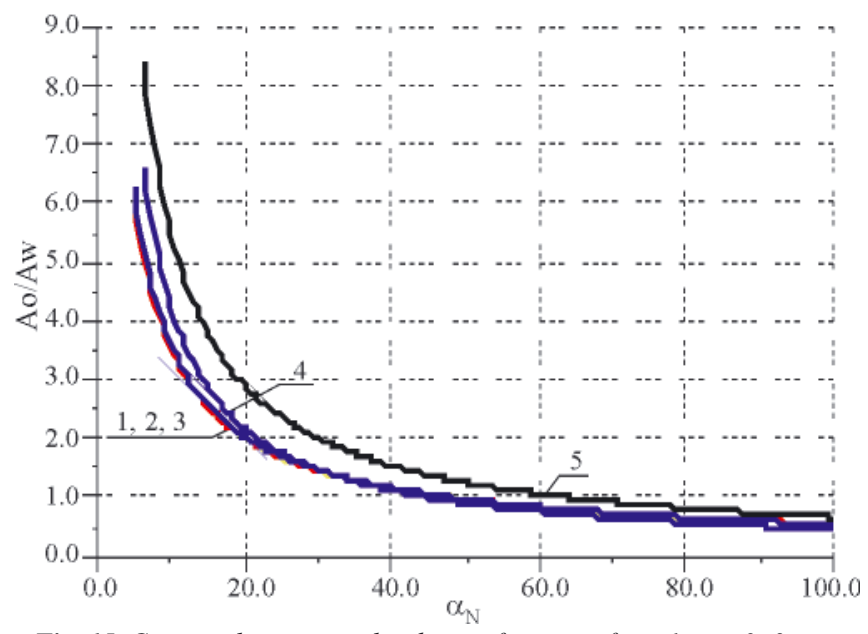

Fig. 15. Casing vibration amplitude as a function of $\alpha_{N} .1: c=0 ; 2: c=$ $10^{-6} ; 3: c=10^{-5} ; 4: c=10^{-4} ; 5: c=10^{-3}$

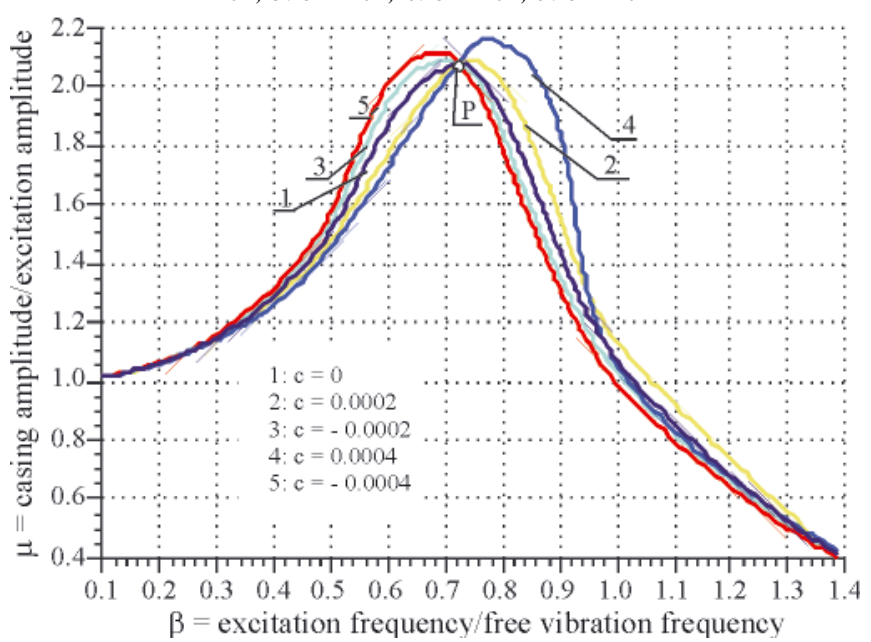

Fig. 16. Amplitude-frequency characteristics for different $c$ values

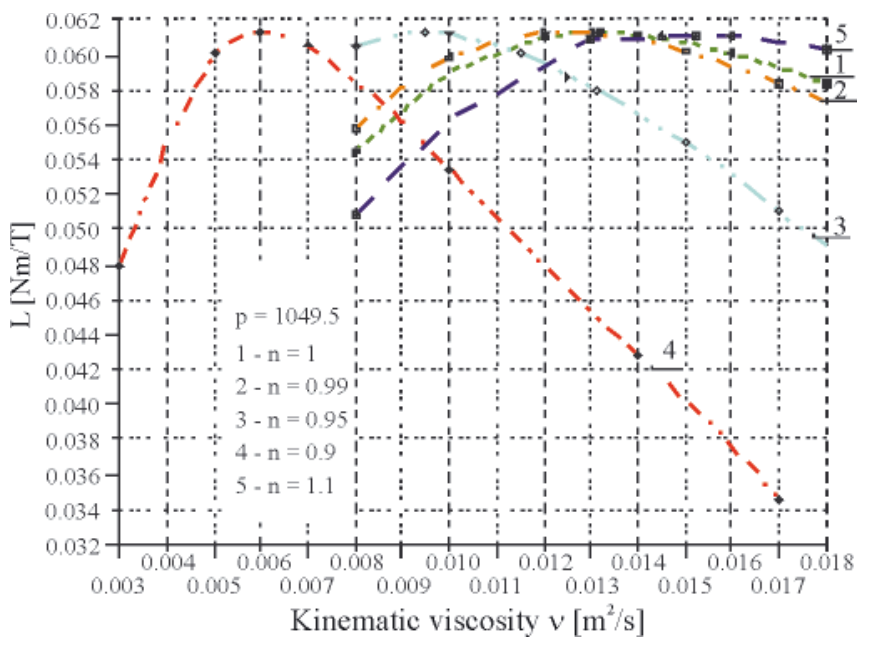

Fig. 17. Work L vs. kinematic viscosity

Before the damper is finally allowed to be used in a given power transmission unit, each respected producer of dampers looks for confirmation of his theoretical analyses in experimental tests, also those performed on a real object, if possible. The results of these tests provide opportunities for final verification of the already performed theoretical analyses of vibration dampers.

The tests are oriented on determining the amplitudefrequency characteristics of the examined dampers. These characteristics, complemented by such damper parameters as: - $\mathrm{I}_{\mathrm{p}}$ - mass moment of inertia of the ring in the damper,

- $\mathrm{I}_{\mathrm{ow}}-$ mass moment of inertia of the casing, 
- $\eta$ - viscosity of the silicone oil,

compose the "metric" of the damper, which should be made available by each producer of vibration dampers.

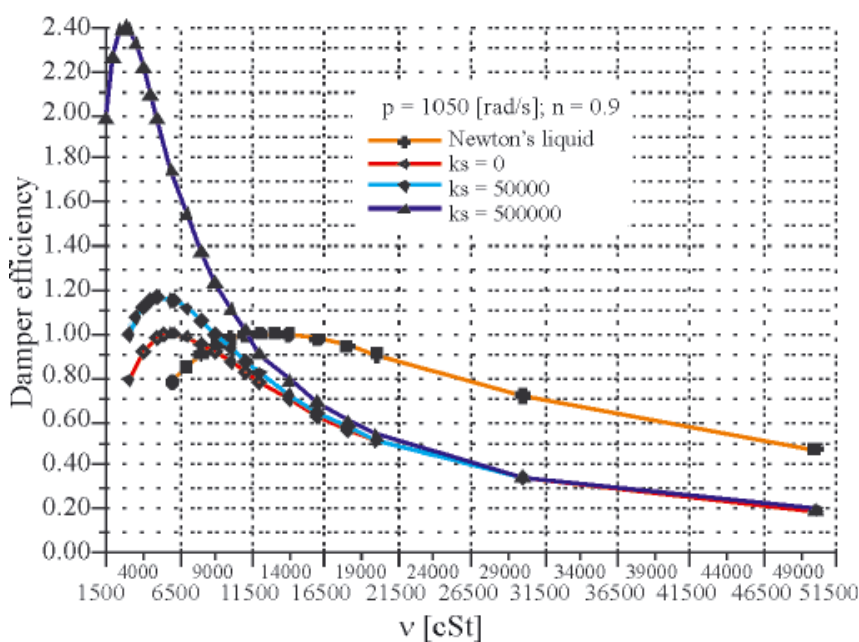

Fig. 18. Damper efficiency as a function of kinematic viscosity $v$ for liquid with $n=0.9$

Damper tests which make it possible to work out their amplitude-frequency characteristics are most frequently done in temperatures close to those in which the damper is expected to work most often (different operating conditions are expected for a damper used in watercraft power transmission systems or electric current generation units, and different for that working in power transmission systems in vehicles).

In order to illustrate the differences in amplitude-frequency characteristics between different dampers, a series of viscotic dampers:

- TW 30 - viscotic damper with damping liquid of viscosity of 30000 [cSt],

- TW 60 - viscotic damper with damping liquid of viscosity of 60000 [cSt],

- TW 100 - viscotic damper with damping liquid of viscosity of 100000 [cSt]

- TW 130 - viscotic damper with damping liquid of viscosity of 130000 [cSt],

- TW 160 - viscotic damper with damping liquid of viscosity of 160000 [cSt],

- TW 200 - viscotic damper with damping liquid of viscosity of 200000 [cSt],

- TW seized,

having the same geometric parameters were tested at three different operating temperatures:

- ambient temperature $25^{\circ} \mathrm{C}$,

- mean operating temperature $45^{\circ} \mathrm{C}$,

- saturation temperature $80^{\circ} \mathrm{C}$,

within the range of the exciting frequencies changing between 25 and $300[\mathrm{~Hz}]$. These frequencies were introduced to the shaft of the research rig using the motor TYP FD. The parameter which was measured in the tests was the torsional vibration of the damper hub which was directly connected to the vibrating shaft.

A brief analysis of the presented results reveals that for each damper at a given temperature there is an optimal viscosity value for which the shaft torsion angle reaches it minimum. It is noteworthy that within the range of lower exciting frequencies, between 25 and $100[\mathrm{~Hz}]$, the viscosity of the damping liquid does not affect remarkably the efficiency of the damper, irrespective of the temperature.

The viscosity of the liquid is decisive for the efficiency of the damper within higher excitation frequency ranges, between 200 and $300[\mathrm{~Hz}]$.

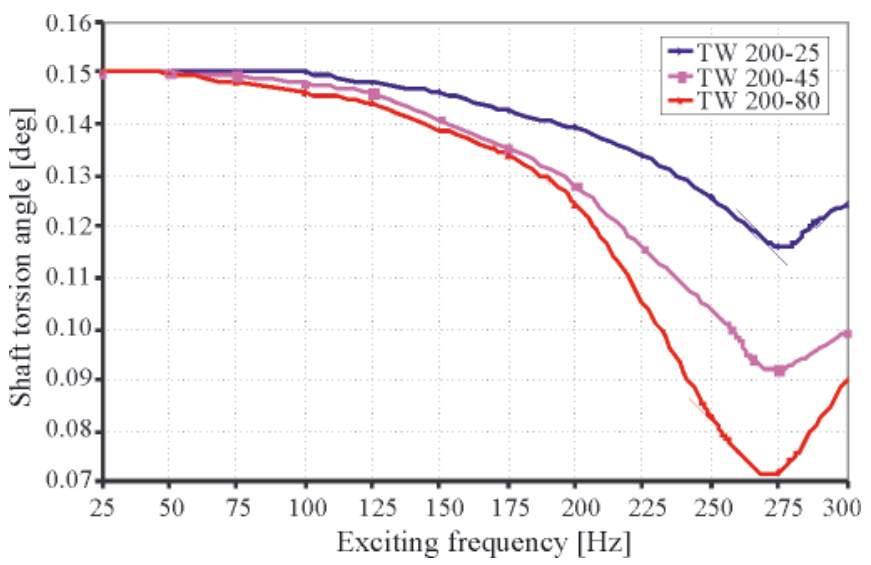

Fig. 19. Comparing amplitude-frequency characteristics of the TW200 damper in temperatures $25^{\circ}, 45^{\circ}, 80^{\circ}[C]$

The amplitude-frequency characteristics provide good opportunities for final selection of optimal viscosity of the liquid in a damper which damps torsional crankshaft vibrations in an electric current generator unit which most often works with constant rotational speed (and practically constant excitation frequency). It is much more difficult to select the optimal liquid viscosity for a damper used for damping torsional crankshaft vibrations in a marine engine and, perhaps most of all, a motor-car engine in which the excitation frequency changes with rotational speed changes. In those cases the practically optimal viscosity is calculated for most dangerous excitation frequency (resonance).

The optimal damping is calculated using the formula:

$$
\alpha_{\mathrm{opt}}=\mathrm{I}_{\mathrm{p}} \omega_{\mathrm{o}}
$$

where:

$\omega_{0}-$ real frequency at which hub vibration is the smallest, $\mathrm{I}_{\mathrm{p}}-$ mass moment of inertia of the inertial ring.

For instance, the optimal viscotic damping $\alpha_{\mathrm{opt}}$ for the damper TW 130 at temperature of $45^{\circ} \mathrm{C}$ is:

$$
\alpha_{\text {opt }_{\mathrm{Tw} 130}}(45)=0.006750877 \cdot 1650=11.195[\mathrm{Nms}]
$$

\section{CONCLUSIONS}

- In order to confirm the theoretical analyses and the result obtained in the experiments done on a model research rig, investigations were performed on a real object, which was a car VW Passat with the engine cubic capacity of 3.61 and power of 290 [KM]. A parameter which was recorded during the tests performed in the engine test house was the amplitude of the torsional vibration of the free shaft end, within the engine rotational speed ranging between 700 and 6100 [rev/min].

- The harmonic analysis of the signal recorded during the tests has revealed, most of all, that the examined dynamic system cannot safely work without a torsional vibration damper, especially when the rotational speed exceeds 3500 [rev/min], and that the biggest threats for the system are the 3-rd and 6-th harmonics.

- Moreover, the tests performed on the real object have confirmed the conclusions resulting from the theoretical analyses and research rig tests about the existence of optimal values of liquid viscosity [4] for which the maximal resonance amplitudes of the engine crankshaft reach their minimum (Fig. 20, 21) 


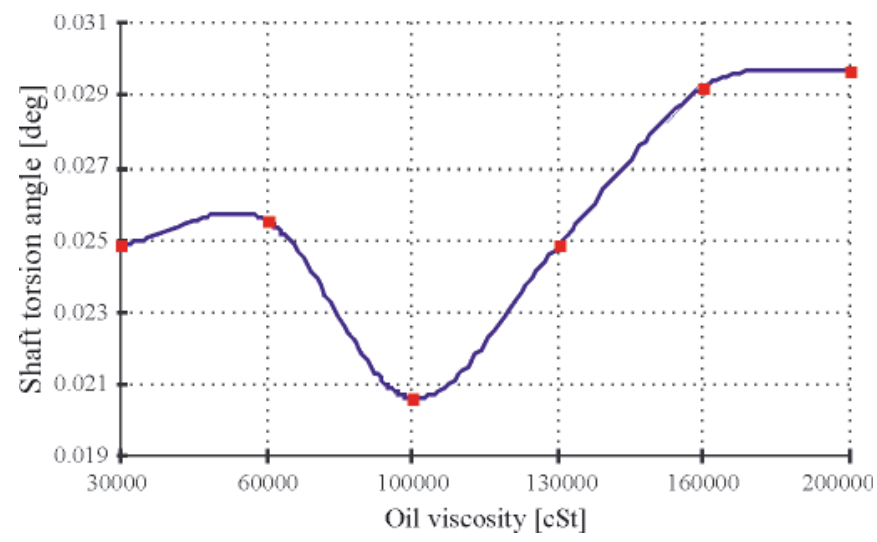

Fig. 20. Shaft torsion angle changes vs. oil viscosity

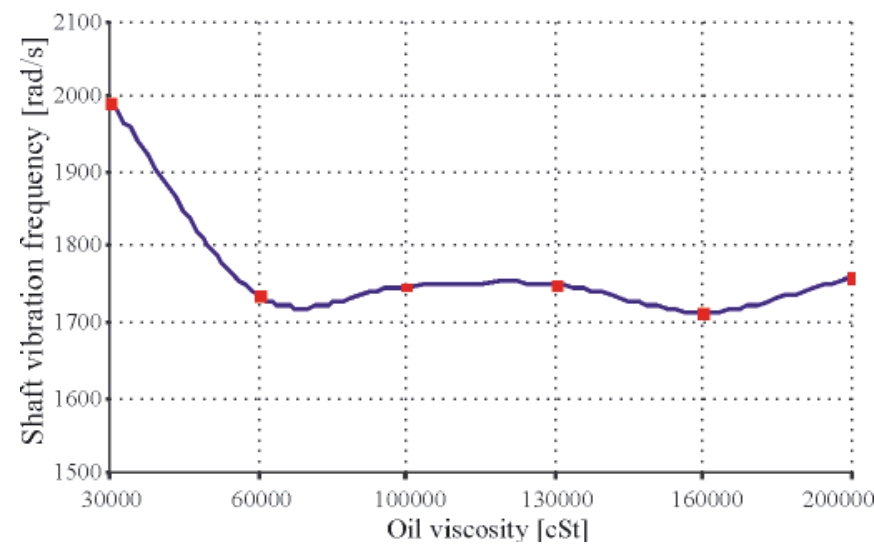

Fig. 21. Shaft vibration frequency changes vs. oil viscosity

- The analysis of the characteristics shown in Figs. 20 and 21 clearly confirms the opinion that the classical viscotic vibration dampers are the optimal dampers only in a very narrow range of frequency excitations, which is caused by the fact that during the operation of the dynamic system we cannot change physical parameters in a viscotic damper (its physical characteristics are constant in practice and cannot be adapted to changing working conditions - changing excitations). That narrow band of efficient operation of these dampers is undoubtedly their disadvantage, but their simple structure and relatively low production costs are the reasons why they are commonly used for damping torsional crankshaft vibrations in power transmission systems.

\section{Notice}

The article was financed by the National Science Centre within the framework of the Research Project no. N N509 547440

\section{BIBLIOGRAPHY}

1. Brun R.: High-speed Diesel engines, (in Polish) WKiL 1973

2. Dąbrowski Z. Maksymiuk M.: Shafts and axles, (in Polish) PWN 1984,

3. Dąbrowski Z.: Machine shafts, (in Polish) PWN 1999

4. Homik W.: Ph.D. thesis: Optimisation of the viscotic torsion damper (in Polish), Rzeszow 1997

5. Homik W.: Design of viscotic torsion dampers (in Polish). Przeglad Mechaniczny 10’ 07

6. Homik. W.: Torsional vibration of the engine crankshaft without damper and with a viscotic vibration damper (in Polish), Przegląd Mechaniczny No. 9' 2008 r.

7. Homik W.: Liquid viscosity changes during the operation of a viscotic vibration damper (in Polish), Przegląd Mechaniczny No. 3' $2009 \mathrm{r}$.

8. Homik W., Szlachta A.: Technology of machining and assembly of viscotic dampers (in Polish), International Scientific Conference, Pro-Tech-Ma 2009

9. Homik W.: Criteria of characteristics evaluation - "quality factor" of the viscotic torsion damper for an internalcombustion engine crankshaft (in Polish), Western Scientific Centre of Ukrainian Transport Academy - Transportna Akademia Ukraini. Praci Zachodnowo Naukowo Centrum No. 19. 2009,

10.Homik W.: Diagnostics, maintenance and regeneration of torsional vibration dampers for crankshafts of ship diesel engines, Polish Maritime Research, No 1/2010

11. Homik W.: Damping of torsional vibration of ship engine crankshafts - general selection methods of viscous vibration damper. Polish Maritime Research, No 3/2011

12.http://www.google.pl/search?q=tw\%C3\%B3rcy+silnik $\% \mathrm{C} 3 \% \mathrm{~B} 3$ $\mathrm{w}+$ spalinowych

13.Jędrzejowski J.: Mechanics of motor-car engine crankshaft assemblies (in Polish)

14.Niewiarowski K.: Piston internal-combustion engines (in Polish), WKiL 1973

15.Wajand J. A., Wajand J. T.: Medium- and high-speed piston internal-combustion engines (in Polish), PWN 1984

16.Wajand J.A.: Diesel engines (in Polish), WKiL 1973

\section{CONTACT WITH THE AUTHOR}

Wojciech Homik, Ph. D.

Rzeszów University of Technology

The Faculty of Mechanical Engineering and Aeronautics

Al. Powstańców Warszawy 8,

35-959 Rzeszów, POLAND

tel.: +48178651100 w. 1637, +48178651637

e-mail: whomik@prz.edu.pl

e-mail:whomik@interia.pl 